\title{
HEPES NA PRODUÇÃO DE EMBRIÕES BOVINOS IN VITRO ${ }^{1}$
}

\author{
HEPES ON IN VITRO PRODUCTION OF BOVINE EMBRYOS
}

\author{
Marcelo Marcos Montagner ${ }^{2}$ Paulo Bayard Dias Gonçalves ${ }^{3}$ Jairo Pereira Neves ${ }^{3}$ \\ Luís Fabiano Santos da Costa ${ }^{4}$ Ederson Bisognin Bortolotto $^{4}$ \\ Alexandre Morales Farias ${ }^{5}$ Patrícia Stranieri $^{5}$
}

\section{RESUMO}

O objetivo do presente estudo foi de avaliar a amplitude da variação de pH em meios de maturação e de cultivo embrionário, com diferentes concentrações do tampão HEPES. Inicialmente, foi determinado o efeito de diferentes concentrações de HEPES $(0,12,5$ e 25,0mM) na variação do pH dos meios de maturação (TCM-199 modificado) e desenvolvimento embrionário (KSOM modificado) em meio ambiente, à temperatura de $25^{\circ} \mathrm{C}$, e na estufa, em uma atmosfera de $5 \%$ de $\mathrm{CO}_{2}$ em ar a $39^{\circ} \mathrm{C}$. Em um segundo experimento, os oócitos foram maturados em TCM-199 modificado sem HEPES (142 oócitos) ou com 25,0mM de HEPES (137 oócitos) e foi avaliado índice de blastocisto. $O$ meio Fert-TALP foi utilizado para a fecundação, sendo que os embriões foram co-cultivados com células epiteliais de oviduto (CEO) em KSOM modificado com 10\% de SFB. Um terceiro experimento foi delineado para determinar a importância da presença do HEPES no meio de cultivo embrionário sobre o desenvolvimento de embriões bovinos in vitro. Para isso, após a retirada do cumulus, os zigotos foram divididos ao acaso e co-cultivados com CEO em KSOM modificado (com 10\% de SFB) sem HEPES (grupo controle; $n=95$ ) ou com 25,0mM de HEPES (grupo HEPES; $n=92$ ). Foram mantidos em cultivo somente os embriões com duas ou mais células, sendo considerados desenvolvidos os que atingiram o estádio de blastocisto expandido (Bx), 7 e 9 dias após inseminação. $O$ cultivo dos oócitos e embriões, em ambos os experimentos, foi efetuado em estufa a $39^{\circ} \mathrm{C}$, com uma atmosfera contendo $5 \%$ de $\mathrm{CO}_{2}$ e umidade saturada. Os resultados mostram que os meios contendo 25,0mM de HEPES foram mais eficientes em minimizar a variação do $\mathrm{pH}$ que os meios com 12,5mM ou sem HEPES. Além disso, a adição de HEPES ao meio de maturação aumentou os índices de Bl sobre o total de oócitos e sobre o total de clivados $(21,9 \%$ e 42,86\%) com relação ao controle $(10,56$ e 16,67\%; $p<0,05)$. Na determinação da importância do HEPES no desenvolvimento embrionário, o grupo HEPES apresentou índices superiores de Bx $(45,65 \%)$ em relação ao controle $(11,58 \% ; p<0,01)$. A uniformidade dos resultados foi um dos aspectos positivos observados quando o HEPES estava presente no meio de cultivo embrionário. Portanto, o uso do HEPES, durante a maturação e o cultivo embrionário, é recomendável para o aumento da produção de embriões in vitro com maior repetibilidade.

Palavras-chave: $p H$, maturação de oócitos, embriões, fecundação in vitro.

\section{SUMMARY}

The aim of the present study was to evaluate the range of $\mathrm{pH}$ changes in maturation and embryo development media, buffered with different HEPES concentrations. Initially, the effect of different concentrations of HEPES (0, 12.5 and $25.0 \mathrm{mM}$ ) on the variation of $\mathrm{pH}$ in the maturation (modified TCM-199) and embryonic development (modified KSOM) media was evaluated at room temperature $\left(25^{\circ} \mathrm{C}\right)$ and in an atmosphere of $5 \% \mathrm{CO}_{2}$ in air at $39^{\circ} \mathrm{C}$. In another experiment, the effect of HEPES on in vitro oocyte maturation was determined. Oocytes were maturated in TCM-199 modified either with 25.0mM of HEPES (HEPES group; $n=137$ ) or without HEPES (control group; $n=142$ ), performing 7 replicates and evaluating the rate of blastocyst. In this study, the medium used for fertilization was Fert-TALP while for embryo development was KSOM with $10 \%$ of fetal bovine serum with monolayer of oviduct epithelial cells. A third experiment was designed to determine the effect of HEPES on embryo development. The zygotes were divided in two groups and co-incubated with oviduct epithelial cells in modified KSOM with $10 \%$ of fetal bovine serum without HEPES $(n=95)$ or with 25.0mM of HEPES $(n=92)$. For this experiment, it was used embryos with two or more cells and the embryo development was considered from cleavage to expanded blastocyst (Bx), 7 and 9 days after insemination. The oocytes and embryos were incubated at temperature of $39^{\circ} \mathrm{C}$, an atmosphere containing $5 \% \mathrm{CO}_{2}$ in air

${ }^{1}$ Trabalho realizado com suporte financeiro da FAPERGS e FINEP.

${ }^{2}$ Médico Veterinário, MSc., Universidade Federal de Santa Maria (UFSM).

${ }^{3}$ Professor Titular, Dr., Departamento de Clínica de Grandes Animais, Centro de Ciências Rurais, UFSM, 97105-900, Santa Maria, RS.

E-mail: bayard@lince.hcv.ufsm.br. P.B.D. Gonçalves, autor para correspondência.

${ }^{4}$ Médico Veterinário, Aluno de Mestrado do Programa de Pós-graduação em Medicina Veterinária, UFSM.

${ }^{5}$ Aluno do Curso de Graduação em Medicina Veterinária, UFSM, Bolsista de Iniciação Científica - CNPq.

Recebido para publicação em 13.01.99. Aprovado em 29.09.99 
and saturated humidity. The media with 25.0mM of HEPES were more efficient in minimizing the range of $\mathrm{pH}$ than those with $12.5 \mathrm{mM}$ or without HEPES. To determine the effect of HEPES during in vitro oocyte maturation, the percentage of $\mathrm{Bl}$ considered either the total number of oocytes or the total number of cleavages was higher in the HEPES group $(21.9 \%$ or $42.9 \%$, respectively) than those obtained in the control group $(10.56 \%$ or $16.67 \%$, respectively). When HEPES was added to embryo culture medium, the percentage of Bx $(45.65 \%)$ was higher than that obtained in medium without HEPES (11.58\%; $p<0.01)$. The variability between replicates was lower when HEPES was present in embryo development medium, comparing to the medium without HEPES. Therefore, HEPES is an important compound to be present in media for oocyte maturation and embryo development, increasing the in vitro production of bovine embryos.

Key words: $p H$, oocyte maturation, embryos, in vitro fertilization

\section{INTRODUÇÃO}

A produção de embriões in vitro (PIV) está se constituindo em um instrumento auxiliar no melhoramento animal e é uma ferramenta com potencial para a formação de bancos de germoplasma na preservação de animais em extinção (PIETERSE \& KAPPEN, 1988; FOOTE, 1996). Entretanto, existem limitações associadas aos processos envolvidos na PIV. Os principais problemas estão relacionados com a baixa eficiência na produção de blastocistos a partir dos oócitos que são submetidos à maturação in vitro e com a variabilidade do processo (FUKUI et al., 1991; CAROLAN et al., 1995; LIU \& FOOTE, 1995). Além disso, os embriões PIV possuem menor viabilidade e menor resistência ao congelamento (GALLI \& LAZZARI, 1996; HASLER, 1996).

Um fator importante para que se obtenha bons resultados na PIV, com relação à quantidade e qualidade dos embriões, é a menor amplitude de variação do pH dos meios (FUKUI et al., 1991; VAJTA et $\boldsymbol{a l} .$, 1997), sendo o pH ideal entre 7,3 e 7,5 (HARPER, 1994; DOWNS \& MASTROPOLO, 1997; VAJTA et al., 1997). Porém, quando se realizam manipulações inerentes ao processo, os meios são submetidos a variações do $\mathrm{pH}$. O tampão orgânico HEPES ( $N$-(2-hidroxietil)piperazina- $N$ '-(2-ácido etanosulfônico) já é utilizado por inúmeros laboratórios no meio de maturação (GOOD et al., 1966; DOWNS \& MASTROPOLO, 1997). No cultivo de embriões bovinos, o HEPES foi utilizado por GOTO et al. (1992) no meio TCM-199 (12,5mM) e por KESKINTEPE et al. (1995) no meio SOF $(25,0 \mathrm{mM})$. Da mesma maneira, o HEPES foi utilizado no cultivo de embriões de outras espécies como coelhos (LIU $\boldsymbol{e t} \boldsymbol{a l} .$, 1996) e suínos (HAGEN $\boldsymbol{e t} \boldsymbol{a l}$., 1991; POLLARD et al., 1995). Alguns trabalhos demonstraram que ao utilizar HEPES no meio de maturação (KATO \& SEIDEL, 1995) e no meio de cultivo embrionário SOF (KESKINTEPE \& BRACKETT, 1996), há melhores resultados na PIV. No entanto, existem controvérsias quanto ao efeito do HEPES sobre a PIV, pois há trabalhos que demonstram que o HEPES não exerce efeito positivo, ou é até deletério, quando utilizado na concentração de 25,0mM (BAGGER $\boldsymbol{e}$ t al., 1987; KESKINTEPE \& BRACKETT, 1996; DOWNS \& MASTROPOLO, 1997).

Apesar de várias equipes utilizarem HEPES no sistema de produção de embriões in vitro de diferentes espécies, não há estudos sobre a influência da adição de HEPES no meio KSOM, utilizado para o desenvolvimento embrionário em bovinos. Assim sendo, foram delineados experimentos para avaliar o efeito da adição de HEPES nos meios de maturação (TCM-199 modificado) e de cultivo embrionário (KSOM modificado) sobre a variação de $\mathrm{pH}$ durante a PIV e, conseqüentemente, sobre os índices de desenvolvimento embrionário. Também, foi avaliada a influência de alterações ambientais sobre o pH dos meios TCM-199 e KSOM modificados, contendo diferentes concentrações de HEPES.

\section{MATERIAL E MÉTODOS}

Os oócitos, aspirados de folículos ovarianos com diâmetro entre 2 e $8 \mathrm{mM}$, foram selecionados e maturados in vitro. A maturação dos oócitos foi realizada, durante 22 a 24 horas, em TCM-199 ${ }^{1}$ modificado, contendo $25,0 \mathrm{mM}$ de $\mathrm{HEPES}^{2}, 2,2 \mathrm{mg}$ de bicarbonato de sódio $3 / 100 \mathrm{~m} \ell, 5 \mu \mathrm{g}$ de $\mathrm{LH}^{4} / \mathrm{m} \ell, 0,5 \mu \mathrm{g}$ de $\mathrm{FSH}^{4} / \mathrm{m} \ell$ e $10 \%$ de soro fetal bovino ${ }^{5}$. Para a maturação, fecundação e desenvolvimento embrionário, o cultivo foi efetuado em gotas de $200 \mu \mathrm{l}$ de meio, em placas de petri $(60 \mathrm{mM})$, sob óleo de silicone e a incubação foi efetuada a $39^{\circ} \mathrm{C}$ em uma atmosfera contendo $5 \%$ de $\mathrm{CO}_{2}$ e umidade saturada. Durante a PIV, foi preferencialmente mantida a relação de 1 oócito ou embrião para cada $10 \mu \ell$ de meio. Um pool de sêmen congelado foi utilizado para a fecundação in vitro em todos os experimentos. A seleção dos espermatozóides foi realizada com a passagem do sêmen por gradientes de percol (ROSENKRANS et al., 1993; SCHWEITZER, 1996). A inseminação (dia 0 da PIV) foi efetuada com a concentração de $2 \times 10^{6}$ espermatozóides/m $\ell$ de meio Fert-TALP contendo $10 \mu \mathrm{g}$ de heparina/m $\ell$. O tempo de co-cultivo de espermatozóides e oócitos foi de 18 a 22 horas.

Após o período de fecundação, as células do cumulus foram retiradas com micropipeta e os possíveis zigotos de cada grupo foram lavados 3 
vezes e colocados em gotas com $200 \mu \ell$ de meio de cultivo embrionário KSOM modificado com $10 \%$ de soro fetal bovino, na presença de monocamada de células epiteliais de oviduto (SCHWEITZER, 1996). Passadas 48 horas da inseminação, somente as estruturas embrionárias com duas ou mais células foram mantidas na gota de co-cultivo e o desenvolvimento embrionário foi avaliado aos dias 7 e 9 após a inseminação, para a observação de blastocistos (Bl) e blastocistos expandidos (Bx), respectivamente.

Em um primeiro experimento, foi determinado o perfil da variação do $\mathrm{pH}$ dos meios de maturação TCM-199 modificado (com 10\% de soro fetal bovino, SFB) sem HEPES (controle), com 12,5 de HEPES e com 25,0mM de HEPES, sob a influência do tempo de permanência em diferentes ambientes. Para isso, foram efetuadas 9 medições de $\mathrm{pH}$ em diferentes tempos de permanência no meio ambiente, à temperatura de $25^{\circ} \mathrm{C}$, e dentro da estufa, em uma atmosfera de $5 \%$ de $\mathrm{CO}_{2}$ em ar e temperatura de $39^{\circ} \mathrm{C}$. Foram efetuadas 3 replicações, sendo que, em cada uma, foram preparadas 9 alíquotas de $3 \mathrm{~m} \ell$ de meio, que foram mantidas em placas de petri $(35 \mathrm{mM})$. Em um período de 90 minutos que antecedeu o experimento, o pH das 27 alíquotas foi estabilizado dentro da estufa. Após, as alíquotas foram retiradas da estufa e a medição do $\mathrm{pH}$ foi efetuada nos períodos 0,15 e 30 minutos em meio ambiente. Passados 30 minutos, 2 alíquotas foram mantidas em meio ambiente (para medições aos 60 e 120 minutos) e as outras 4 alíquotas de cada meio foram recolocadas na estufa e o pH foi medido depois de 15, 45 e 90 minutos de permanência na estufa. Posteriormente, os meios foram retirados da estufa e deixados no meio ambiente por mais $30 \mathrm{mi}-$ nutos, quando foi realizada a medição final. A medição do $\mathrm{pH}$ foi realizada com os meios no interior de tubos de ensaio, sendo os $3 \mathrm{~m} \ell$ de cada alíquota transferidos rapidamente da placa de petri para o interior do tubo. Seguindo os mesmos procedimentos, foi também verificado o perfil da variação do $\mathrm{pH}$ dos meios de cultivo embrionário KSOM modificado com $10 \%$ de SFB, sem HEPES (controle), com 12,5 de HEPES e com 25,0mM de HEPES, em 3 replicações.

Em um segundo experimento, foi avaliado o efeito do tampão HEPES no meio de maturação sobre a produção de Bl. Foram efetuadas 7 replicações, sendo os oócitos divididos em dois grupos de forma aleatória. No grupo controle, foram maturados 142 oócitos em TCM-199 modificado sem HEPES e, no grupo tratamento, foram maturados 137 oócitos em TCM-199 modificado contendo 25,0mM de HEPES. Neste experimento, os embriões foram cultivados em KSOM modificado sem HEPES.
Finalmente, um terceiro experimento foi delineado para avaliar o efeito da presença do HEPES no meio de cultivo embrionário sobre a formação de blastocisto expandido, 9 dias após a inseminação in vitro. Nesse estudo, foram realizadas 3 replicações. Os oócitos foram maturados em TCM-199 modificado com $25 \mathrm{mM}$ de HEPES. Após a retirada do cumulus, os zigotos foram divididos ao acaso e cultivados em KSOM modificado com $10 \%$ de SFB (grupo controle) ou em KSOM modificado com 10\% de SFB e 25,0mM de HEPES (grupo HEPES). No momento da avaliação da clivagem, só permaneceram em cultivo os embriões com duas ou mais células e o desenvolvimento embrionário foi considerado a partir de embriões clivados (95 embriões no grupo controle e 92 no grupo HEPES).

Para a realização da análise estatística do primeiro experimento, os dados foram, inicialmente, submetidos a uma análise de heterogeneidade das curvas. Quando as curvas foram homogêneas, realizou-se a análise de covariância no PROC GLM, no programa estatístico SAS, empregando o seguinte modelo estatístico:

$$
Y_{i j}=\mu+\alpha_{i}+\beta_{j} X_{i j}+\epsilon_{i j}
$$

onde $\mathrm{Y}_{\mathrm{ij}}$ é o $\mathrm{pH}$ dos meios, $\mu$ é a constante comum a todas as observações, $\alpha_{i}$ corresponde aos diferentes meios analisados, $\beta_{\mathrm{j}}$ é o coeficiente de regressão para a relação entre $\mathrm{Y}$ e $\mathrm{X}$, sendo que $\mathrm{X}_{\mathrm{ij}}$ corresponde aos diferentes tempos e $\epsilon_{\mathrm{ij}}$ é o efeito residual. Ao se constatar a heterogeneidade das curvas, a análise foi realizada através de análise de variância, após os dados serem transformados pelo PROC RANK e as diferenças entre as médias comparadas por meio de contrastes no programa estatístico SAS, com o seguinte modelo estatístico:

$$
\mathrm{Y}_{\mathrm{ijk}}=\mu+\alpha_{\mathrm{i}}+\beta_{\mathrm{j}}+(\alpha \beta)_{\mathrm{ij}}+\epsilon_{\mathrm{ijk}}
$$

onde $\mathrm{Y}_{\mathrm{ijk}}$ é o pH e o ${ }_{\mathrm{k}}$ é o número de replicações, $\mu$ é a constante comum para todas as observações, $\alpha_{i}$ é o grupo, $\beta_{\mathrm{j}}$ é o tempo, $(\alpha \beta)_{\mathrm{ij}}$ é a interação entre grupo e o tempo e $\in_{\mathrm{ijk}}$ é o efeito do resíduo.

No segundo e terceiro experimentos, o delineamento experimental utilizado foi o de blocos inteiramente casualizados. Os diferentes tratamentos foram realizados simultaneamente, sendo que cada replicação foi considerada um bloco. Os resultados em percentagens foram transformados pelo PROC RANK, no programa estatístico SAS, com a finalidade de aplicação de testes paramétricos para a análise dos resultados. O modelo estatístico para análise dos resultados foi o seguinte:

$$
Y_{i j}=\mu+\alpha_{i}+\beta_{j}+\epsilon_{i j}
$$


onde $\mathrm{Y}_{\mathrm{ij}}$ é a variável dependente, $\boldsymbol{\mu}$ é a constante comum para todas as observações, $\alpha_{i}$ é o efeito dos tratamentos, $\beta_{\mathrm{j}}$ é o efeito dos blocos e o $\in_{\mathrm{ij}}$ é o efeito do resíduo.

\section{RESULTADOS}

No primeiro experimento, o perfil da variação do $\mathrm{pH}$ foi influenciado pelos meios de maturação e de cultivo embrionário e pelo tempo de permanência em ambientes com diferente concentração de $\mathrm{CO}_{2}$ e temperatura. Os períodos de medição do $\mathrm{pH}, 0,15,30,60$ e 120 minutos de permanência em meio ambiente a $25^{\circ} \mathrm{C}$, forneceram curvas heterogêneas e os meios com 25,0mM de HEPES apresentaram menor variação de $\mathrm{pH}$ que os meios sem HEPES ou com 12,5mM de HEPES ( $p=0,0001$ ), sendo que os meios com $12,5 \mathrm{mM}$ tiveram menor variação que os sem HEPES ( $p=0,0001$; Figura 1). Quando se avaliou o pH dos meios de maturação e cultivo embrionário sem HEPES, com 12,5mM de HEPES ou com 25,0mM de HEPES, submetidos a diferentes períodos de permanência dentro e fora da estufa, ou seja, $0,15,30$ (em meio ambiente a $25^{\circ} \mathrm{C}$ ), $45,75,120$ (referentes a 15,45 e 90 minutos a $5 \%$ $\mathrm{CO}_{2}$ e $39^{\circ} \mathrm{C}$ ) e 150 minutos (referente a 30 minutos em meio ambiente a $25^{\circ} \mathrm{C}$ ), as curvas obtidas foram homogêneas. Os meios de maturação contendo 25,0mM e 12,5mM de HEPES apresentaram um perfil do $\mathrm{pH}$ mais estável que o controle $(\mathrm{p}<0,01 \mathrm{e}$

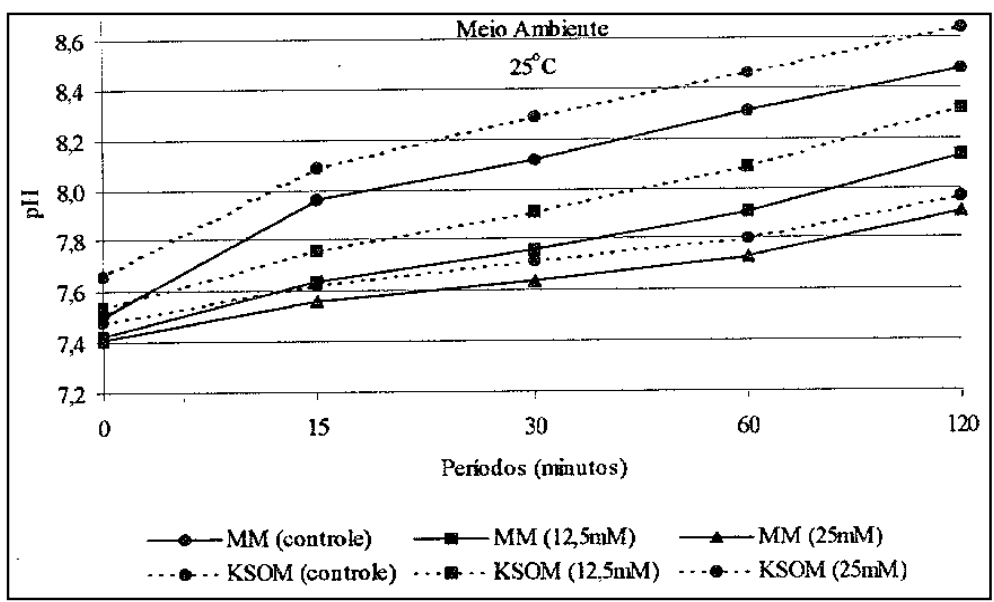

Figura 1 - Perfil da variação do pH dos meios de maturação TCM-199 modificado (MM) e de cultivo embrionário KSOM modificado, ambos com $10 \%$ de SFB, sem HEPES (controle), com $12,5 \mathrm{mM}$ de HEPES e com $25,0 \mathrm{mM}$ de HEPES, em diferentes pontos de medição relativos a minutos de permanência em meio ambiente $\left(25^{\circ} \mathrm{C}\right)$. Os valores correspondem às médias de 3 replicações. O erro padrão da média foi menor que 0,05 para todos os valores. As curvas foram heterogêneas $(\mathrm{p}<0,012)$ e os meios com $25,0 \mathrm{mM}$ de HEPES apresentaram menor variação de $\mathrm{pH}$ que os outros grupos ( $\mathrm{p}=0,0001$ ), sendo que os meios contendo $12,5 \mathrm{mM}$ de HEPES, também variaram menos que o controle $(\mathrm{p}=0,0001)$. $\mathrm{p}<0,05$ respectivamente; figura 2). Da mesma forma, os meios KSOM modificado contendo $25,0 \mathrm{mM}$ ou 12,5mM de HEPES, também apresentaram um perfil do $\mathrm{pH}$ mais estável que o controle $(\mathrm{p}<0,001$ e $\mathrm{p}<0,02$ respectivamente; figura 2 ). Não houve diferença estatística entre os grupos com $25,0 \mathrm{mM}$ e 12,5mM de HEPES, mas, em alguns pontos das curvas, observou-se que o $\mathrm{pH}$ dos meios com $2,5 \mathrm{mM}$ variou mais, ficando mais alto que o dos 25,0mM. Por exemplo, no ponto 150 da urva dos meios de cultivo embrionário, o meio com 12,5mM alcançou um $\mathrm{pH}$ de 7,94, enquanto o meio $25,0 \mathrm{mM}$ alcançou um $\mathrm{pH}$ de 7,72. Independentemente da presença ou não do HEPES, o pH dos meios praticamente atingiu a estabilização após 45 minutos dentro da estufa.

Ao avaliar o HEPES no meio de maturação, os grupos apresentaram índices de clivagem similares, sendo de $51,1 \%$ (70/137) para o grupo que foi adicionado $25,0 \mathrm{mM}$ de HEPES ao meio de maturação e de 63,4\% (90/142) para o grupo controle. No entanto, a adição de HEPES ao meio de maturação aumentou os índices de $\mathrm{Bl}$ sobre o total de oócitos e sobre o total de clivados $(21,9 \% \mp 5,69$ e $42,86 \% \mp$ $11,5)$ em relação ao controle $(10,56 \% \mp 3,83$ e $16,67 \% \mp 5,59 ; \mathrm{p}<0,05)$.

A utilização de $25,0 \mathrm{mM}$ de HEPES no meio de cultivo embrionário forneceu índices superiores de desenvolvimento embrionário até o estágio de $\mathrm{Bx}(45,65 \%)$ em relação ao grupo controle $(11,58 \%$; $\mathrm{p}<0,01$; figura 3$)$. A uniformidade dos resultados, nas três replicações realizadas, foi um dos fatores positivos observados quando $\mathrm{o}$ HEPES estava presente no meio de cultivo embrionário em relação ao grupo controle (Figura 3).

\section{DISCUSSÃO}

O HEPES nos meios de maturação e de cultivo embrionário apresentou efeito tampão de forma dependente da concentração, o qual foi demonstrado pela menor amplitude de variação do $\mathrm{pH}$ nos meios com HEPES (Figuras 1 e 2). Essa menor variação observada, provavelmente, repetiu-se de forma similar e exerceu papel importante durante os períodos de maturação e desenvolvimento embrionário, pois os resultados demonstraram um efeito positivo sobre a produção de embriões com uso do HEPES nos meios de maturação e cultivo embrionário (Figura 3). É 


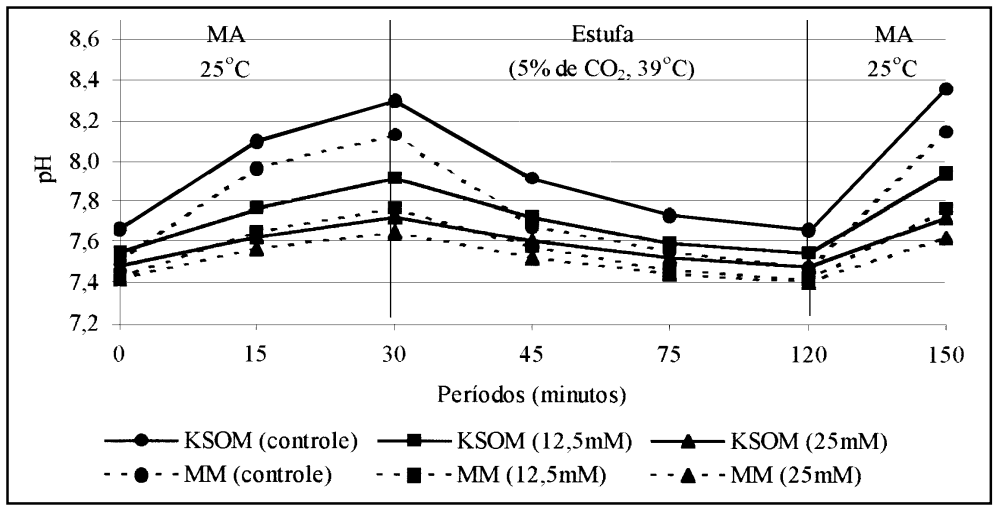

Figura 2 - Perfil da variação do pH dos meios de cultivo embrionário KSOM modificado e de maturação TCM-199 modificado (MM), ambos com 10\% de SFB, sem HEPES (controle), com 12,5mM de HEPES e com 25,0mM de HEPES, em diferentes pontos de medição relativos à permanência em estufa $(5 \%$ de $\left.\mathrm{CO}_{2}, 39^{\circ} \mathrm{C}\right)$ e no meio ambiente $\left(\mathrm{MA} ; 25^{\circ} \mathrm{C}\right)$. Os valores correspondem às médias de 3 replicações e o erro padrão da média foi menor que 0,05 para todos os valores. As curvas produzidas são homogêneas $(p>0,88)$ e os meios com 25,0mM e 12,5mM de HEPES forneceram um perfil do $\mathrm{pH}$ mais estável do que o controle tanto no meio KSOM modificado ( $\mathrm{p}<0,001$ e $\mathrm{p}<0,02$; respectivamente) como no meio TCM-199 modificado ( $p<0,01$ e $p<0,05$; respectivamente), levando em consideração a covariável tempo. Não houve diferença significativa entre os grupos contendo HEPES ( $p>0,05)$.

importante ressaltar que o $\mathrm{pH}$ das soluções e do fluido celular é crítico para a produção de blastocistos (FUKUI $\boldsymbol{e t}$ al., 1991; VAJTA et al., 1997) e o ideal é que ele esteja entre 7,3 e 7,5 (HARPER, 1994; DOWNS \& MASTROPOLO, 1997; VAJTA et al., 1997).

Nas condições deste trabalho, o uso do HEPES na concentração tradicional de $25,0 \mathrm{mM}$ foi extremamente positivo sobre os resultados finais da PIV. Sendo, pela primeira vez, demonstrado o efeito do HEPES em meio KSOM sobre o desenvolvimento embrionário, bem como a demonstração da

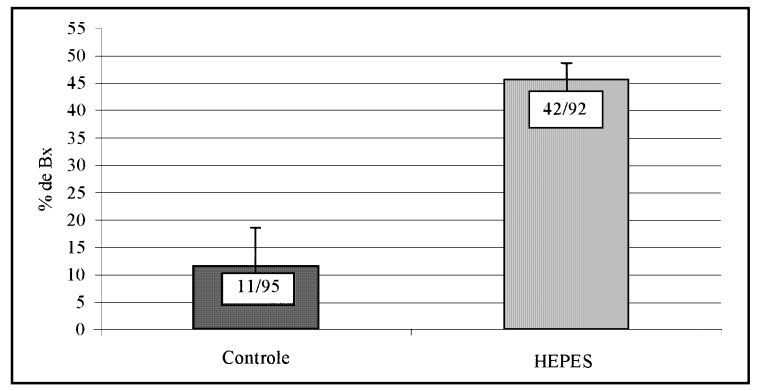

Figura 3 - HEPES no desenvolvimento de embriões bovinos in vitro. A adição de $25,0 \mathrm{mM}$ de HEPES no meio de cultivo embrionário, KSOM com $10 \%$ de SFB (HEPES), forneceu índices superiores de desenvolvimento embrionário até o estágio de blastocisto expandido $(\mathrm{Bx})$ em relação ao grupo sem HEPES (controle; $\mathrm{p}<0,01)$. Cada barra representa a média e o erro padrão da média de 3 replicações. influência de variações ambientais sobre o $\mathrm{pH}$ dos meios TCM-199 e KSOM modificados, com ou sem HEPES. Os índices de $45 \%$ de Bx alcançados (Figura 3), demonstram que o desenvolvimento embrionário foi satisfatório e esteve na média obtida pela maioria das equipes que trabalham com PIV. Ficou determinado que ao baixar a concentração de HEPES, diminui-se a capacidade tampão e, com isso, perde-se a segurança de menor variação de $\mathrm{pH}$ nos meios durante a PIV.

$\mathrm{O}$ efeito benéfico da presença do HEPES e a concentração em que deve ser utilizado parecem depender da espécie, das manipulações e das condições de cultivo para PIV em cada laboratório e, por que não dizer, em cada rotina de PIV, pois há equipes que utilizam em seus sistemas de cultivo para embriões cuniculídeos (2,5mM; LIU et al., 1996) e bovinos (12,5mM; GOTO et al. 1992) concentrações mais baixas que $25,0 \mathrm{mM}$. Além disso, existem trabalhos contraditórios, uns demonstram efeito positivo da presença do HEPES no meio de maturação em bovinos (KATO \& SEIDEL, 1995), no cultivo embrionário em suínos sem suplementação de $\mathrm{CO}_{2}$ (10mM de HEPES; HAGEN $\boldsymbol{e t} \boldsymbol{a l} ., 1991)$ e no cultivo embrionário com meio SOF em bovinos (10mM de HEPES; KESKINTEPE \& BRACKETT, 1996). Outros demonstraram que esse efeito é nulo no meio de fecundação em bovinos (10mM de HEPES; KESKINTEPE \& BRACKETT, 1996) e no cultivo embrionário sem suplementação de $\mathrm{CO}_{2}$ em suínos (20mM de HEPES; POLLARD et al., 1995). Também, há trabalhos demonstrando que a adição de HEPES pode determinar um efeito deletério, pois, em cultivo de oócitos de camundongos, BAGGER $\boldsymbol{e t}$ al. (1987) descreveram que há significativa degeneração dos oócitos e DOWNS \& MASTROPOLO (1997) demonstraram que aumentam os índices de vesícula germinativa. KESKINTEPE \& BRACKETT (1996), também, encontraram efeito prejudicial do HEPES $(25,0 \mathrm{mM})$ no meio de fecundação.

\section{CONCLUSÃO}

A adição de HEPES aos meios para maturação de oócitos (TCM-199 modificado) e desenvolvimento embrionário (KSOM modificado) minimizam a variação de $\mathrm{pH}$, diminuem a variabilidade dos resultados e incrementam os índices de blastocisto. 


\section{AGRADECIMENTO}

Os autores agradecem ao Frigorífico Silva pela cedência dos ovários, à ABS-PECPLAN pelo fornecimento do sêmen e ao NHPP, NIDDK \& Dr. Parlow pela cessão dos hormônios FSH e LH.

\section{FONTES DE AQUISIÇÃO}

${ }^{1}$ Nutricel, Campinas, SP.

${ }^{2}$ Sigma, Estados Unidos

${ }^{3}$ Merck, Alemanha.

${ }^{4}$ NHPP, NIDDK \& Dr. Parlow, Estados Unidos.

${ }^{5}$ Produzido no BioRep - UFSM

\section{REFERÊNCIAS BIBLIOGRÁFICAS}

BAGGER, P.V., BYSKOV, A.G., CHRISTIANSEN, M.D Maturation of mouse oocytes in vitro is influenced by alkalization during their isolation. Journal of Reproduction and Fertility, v.80, p.251-255, 1987.

CAROLAN, C., LONERGAN, P., VAN LANGENDONCKT, A., et al. Factors affecting bovine embryo development in synthetic oviduct fluid following oocyte maturation and fertilization in vitro. Theriogenology, v.43, p.1115-1128, 1995 .

DOWNS, S.M., MASTROPOLO, A.M. Culture conditions affect meiotic regulation in cumulus cell-enclosed mouse oocyte. Molecular Reproduction and Development, v.46, p.551566, 1997.

FOOTE, R.H. Review: Dairy cattle reproductive physiology research and management - past progress and future prospects. Journal of Dairy Science, v.79, p.980-990, 1996

FUKUI, Y., McGOWAN, L.T., JAMES, R.W., et al. Factors affecting the in vitro development to blastocysts of bovine oocytes matured and fertilized in vitro. Journal of Reproduction and Fertility, v.92, p.125-131, 1991.

GALLI, C., LAZZARI, G. Practical aspects of IVM/IVF in cattle. Journal of Reproduction Science, v.42, p.371-379, 1996

GOOD, N.E., WINGET, G.D., WINTER, W., et al. Hydrogen ion buffers for biological research. Biochemistry, v.5, n.2, p.467-477, 1966.

GOTO, K., IWAI, N., TAKUMA, Y., et al. Co-culture of in vitro fertilized bovine embryos with different cell monolayers. Journal of Animal Science, v.70, n.5, p.1449-1453, 1992.

HAGEN, D.R., PRATHER, R.S., SIMS, M.M., et al. Development of one-cell porcine embryos to the blastocyst stage in simple media. Journal of Animal Science, v.69, p.1147-1150, 1991.

HARPER, M.J.K. Gamete and zygote transport. In: KNOBIL, E. NEILL, J. The Physiology of Reproduction. New York : Raven, 1994. Cap. 4. p.123-188.

HASLER, J.F. Commercial production of in vitro-derived bovine embryos. Arquivos da Faculdade de Veterinária UFRGS v.24, n.1, p.117-134, 1996

KATO, H., SEIDEL, G.E. Maturation of bovine oocytes in hepes-buffered medium improves subsequent embryonicdevelopment. Biology of Reproduction, v.55, n.1, p.174, 1995.

KESKINTEPE, L., BRACKETT, B.G. In vitro developmental competence of in vitro-matured bovine oocytes fertilized and cultured in completely defined media. Biology of Reproduction, v.55, n.2, p.333-339, 1996.

KESKINTEPE, L., BURNLEY, C.A., BRACKETT, B.G. Production of viable bovine blastocysts in defined in vitro conditions. Biology of Reproduction, v.52, n.6, p.1410-1417, 1995.

LIU, Z., FOOTE, R.H. Development of bovine embryos in KSOM with added superoxide dismutase and taurine and with five and twenty percent $\mathrm{O}_{2}$. Biology of Reproduction, v.53, p.786-790, 1995.

LIU, Z., FOOTE, R.H., SIMKIM, M.E., et al. Effect of amino acids and alpha-amanitin on the development of rabbit embryos in modified protein-free KSOM with HEPES Molecular Reproduction and Development, v.45, n.2, p.157-162, 1996.

PIETERSE, M.C., KAPPEN, K.A. Aspiration of bovine oocytes during transvaginal ultrasound scanning of the ovaries. Theriogenology, v.30, p.751-762, 1988.

POLLARD, J.W., PLANTE, C., LEIBO, S.P. Comparison of development of pig zygotes and embryos in simple and complex culture media. Journal of Reproduction and Fertility, v.103, p.331-337, 1995.

ROSENKRANS, Jr.C.F., ZENG, G.Q., McNAMARA, G.T., et al. Development of bovine embryos in vitro as affected by energy substrates. Biology of Reproduction, v.49, p.459-462, 1993.

SCHWEITZER, C.M. Recuperação de espermatozóides, capacitação espermática e desenvolvimento embrionário in vitro de bovinos. Santa Maria-RS, 996. 101p. Dissertação (Mestrado em Medicina Veterinária) - Curso de Pósgraduação em Medicina Veterinária, Universidade Federal de Santa Maria, 1996.

VAJTA, G., HOLM, P., GREVE, T., et al. Effect of $\mathrm{pH}$ of culture medium on in vitro development of bovine embryos. Theriogenology, v.47, p.286, 1997. 